Portland State University

PDXScholar

$11-24-1976$

\title{
Figurative Painting and It's Reverberation in Pairs
}

Carol Crampton Adams

Portland State University

Follow this and additional works at: https://pdxscholar.library.pdx.edu/open_access_etds

Part of the Fine Arts Commons, and the Painting Commons Let us know how access to this document benefits you.

\section{Recommended Citation}

Adams, Carol Crampton, "Figurative Painting and It's Reverberation in Pairs" (1976). Dissertations and Theses. Paper 2573.

https://doi.org/10.15760/etd. 2570

This Thesis is brought to you for free and open access. It has been accepted for inclusion in Dissertations and Theses by an authorized administrator of PDXScholar. Please contact us if we can make this document more accessible: pdxscholar@pdx.edu. 
AN ABSTRACT OF THE THESIS OF Carol Crampton Adams for the Master of Fine Arts in Painting presented November 24, 1976. Title: Figurative Painting and Its Reverberation in Pairs. APPROVED BY MEMBERS OF THE THESIS COMMITTEE:
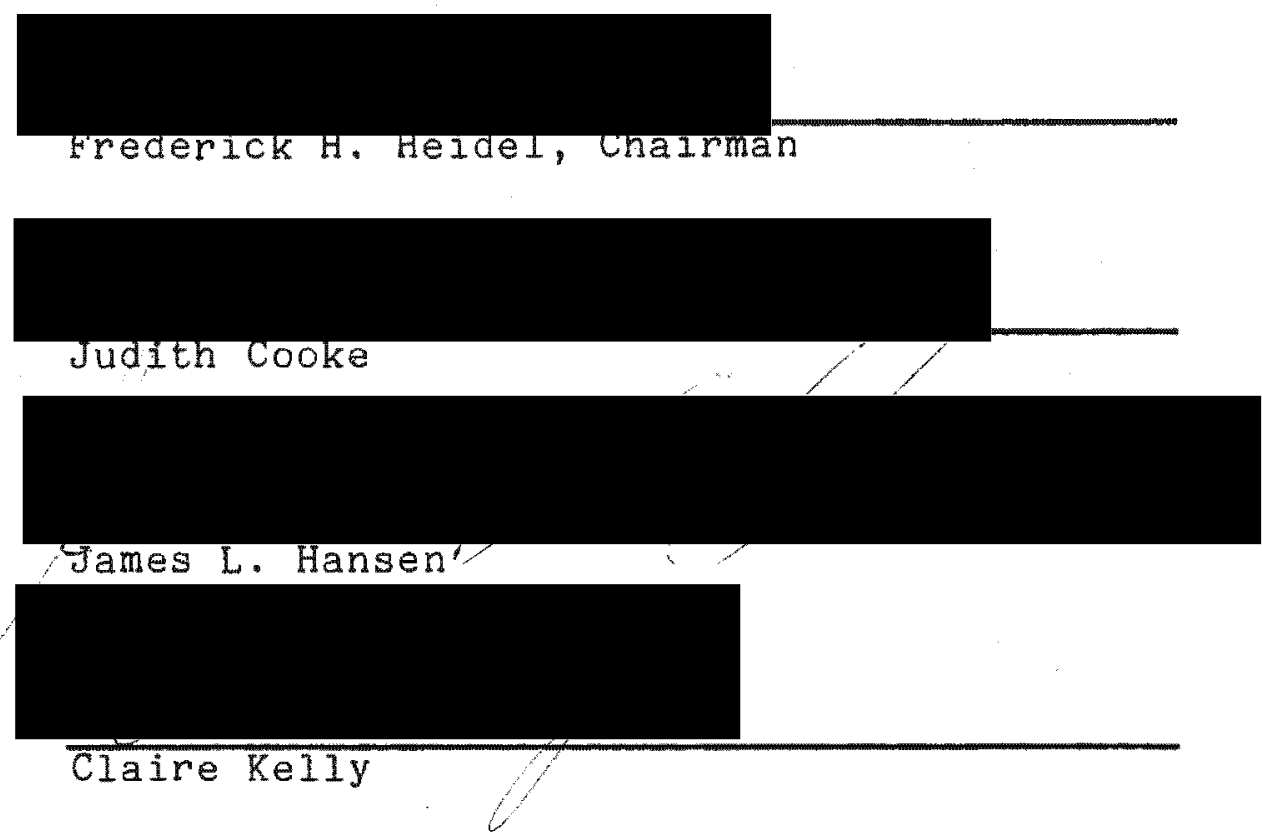

The thesis discusses twelve paintings completed during the period of study from October of 1974 to November of 1976 and presented at the Art and Architecture Gallery, November 8, 1976 - November 26, 1976. 
TO THE OFEICE OF GRADUATE STUDIES AND RESEARCH:

The members of the Committee approve the thesis of Carol Crampton Adams presented November 24, 1976.

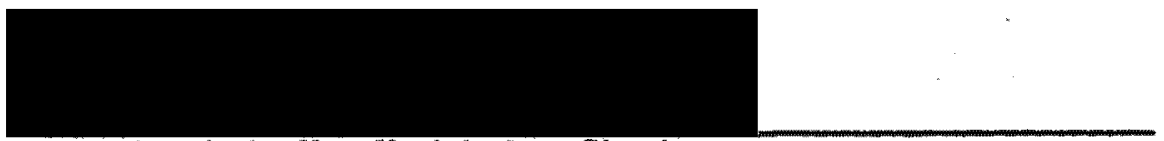

Frederick H. Heidel, Chairman

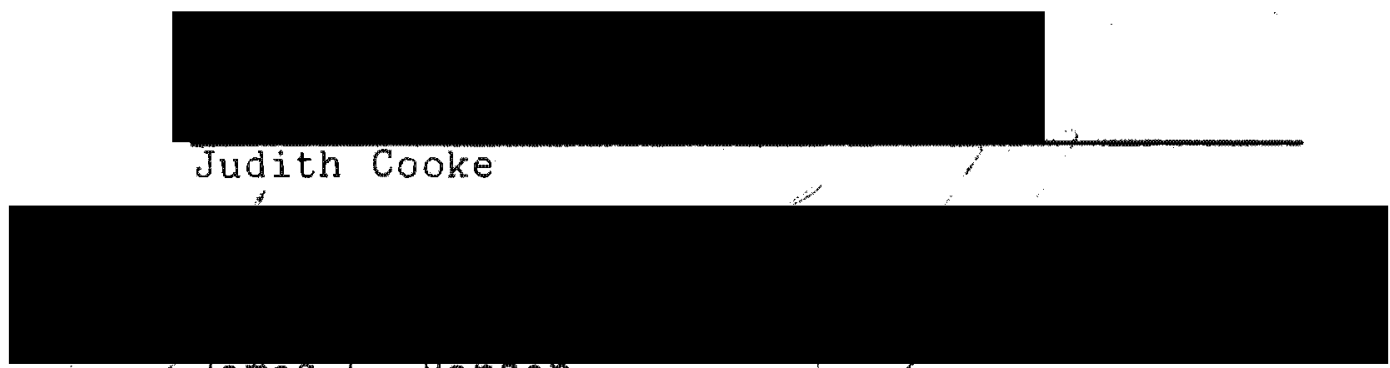

fumes L. Hansen

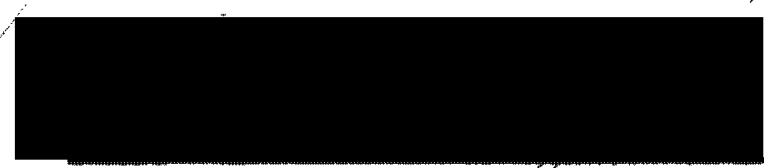

Claire Kelly

APPROVED :

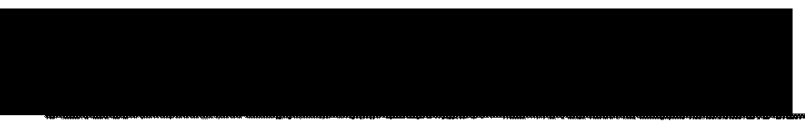

Frederick H. Heidel, Head, Department of Art and Architecture

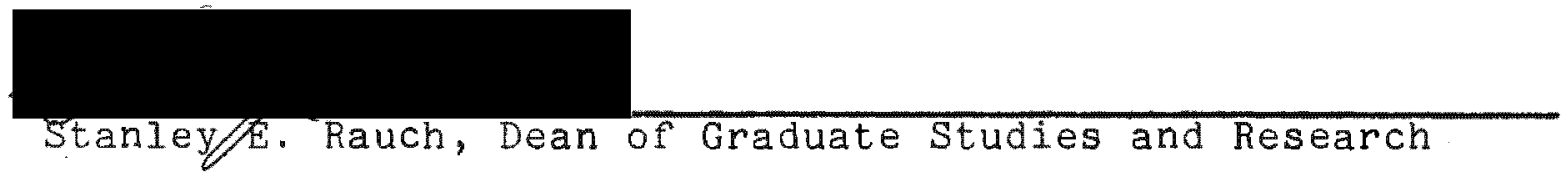




\title{
FIGURATIVE PAINTING AND
}

ITS REVERBERATION IN PAIRS

\author{
by \\ CAROL CRAMPTON ADAMS
}
A thesis submitted in partial fulfillment of the requirements for the degree of

\author{
MASTER OF FINE ARTS \\ IN \\ PAINTING
}

Portland State University

1976 


\section{TABLE OF CONTENTS}

PAGE

LIST OF FIGURES . . . . . . . . . . . . . . iv CHAPTER

I INTRODUCTION . . . . . . . . . . . . I

II DESCRIPTION AND ANALYSIS . . . . . . . 3

II CONCLUSION . . . . . . . . . . 10 


\section{LIST OF FIGURES}

I "Carrott Cake"

II "Cipressa" 6

II "The Mark on the Wall" . . . . . . . 8

IV "Orlando" . . . . . . . . . . . . 12

V "Lily Briscoe" . . . . . . . . . . 13

VI "Nancy" • • • • • . . • • • • • . 14 
CHAPTER I

INTRODUCTION

Jazz, classical music, wine, food, sensuous experience, all become more intricate and involved when another variable is introduced. Immediately an intellectual game begins, the rules are understood. I felt, as a painter, I could conceivably play the game by creating paired canvases instead of individual paintings. The second canvas would increase the variables as comparing this juxtaposition to improvised jazz in which each additional instrument leads to a more exciting composition. However, there are special problems unique to paired paintings, and to me the ultimate one to be considered in achieving successful paired canvases is one of balance.

The meaning of balance is more philosophical than simply the equilibrium of various elements in a painting. It is a more organic expression of striving towards opposition and then returning again to the starting point. Some analogies are: a musician that takes a note and embellishes it, a fish on the end of a pole, a wave on the beach. An idea that is caught, then runs its limit, plays out its possibilities, is in the end, like the wave, brought back into balance. It is the act of testing equilibrium that is exciting. Therefore, I could conceivably play the game, 
using color, line, form, yet introducing another variable, that of another painting, the paired paintings could achieve balance and control. I was curious to experience this game, and following certain rules, grow from the experiment.

The decision to introduce a non-figurative piece gave me the opportunity to paint more abstractly, yet not cut the umbilical cord to the figure completely. I have always done figurative work and figures were the catalyst to begin painting the non-figurative canvas. Also, I wanted the freedom to experience painting without concern for achieving a strong figurative piece in both paintings. The two paintings would not be conventionally related, such as lines continuing across the two surfaces, or the connection of the two by form, but would be related by color and exaggerated or distorted shapes. All in all, I wanted to create two canvases, each an entity in itself, yet connected to each other by a reliance on each other. At the same time the paintings must generate a visually exciting interaction that is open ended and responsive to the viewer. 


\section{DESCRIPTION AND ANALYSIS}

I do not feel the necessity to describe each experience in painting the paired canvases. There were relatively few variations on the theme, so therefore I wish to elaborate on some rather than all of the pairs.. I have chosen "Carrott Cake", "Cipressa", and "The Mark on the Wall" to illustrate my intention stated in the introduction.

The size and shape of the paintings are important, five feet square (152 centimeters by 152 centimeters), practically, life size. It allowed me to use free movements in drawing the figures, forcing me to fill the canvas with the figure and at times running of the canvas. Sometimes the canvas itself dictated the drawing of the figure, so at times I exaggerated the drawing of the figure rather than keeping close to the reality of the pose. My choice to use a square canvas was based on a positive attitude for the shape. I respond to the balance inherent in a square as opposed to the distractions of a rectangle.

In "Carrott Cake" the figure is standing, back to the viewer with arms clasped together. "The different planes created by this pose are treated as abstract forms and play together with the field in which the figure is standing. The vertical thrust of the pose is emphasized more by 


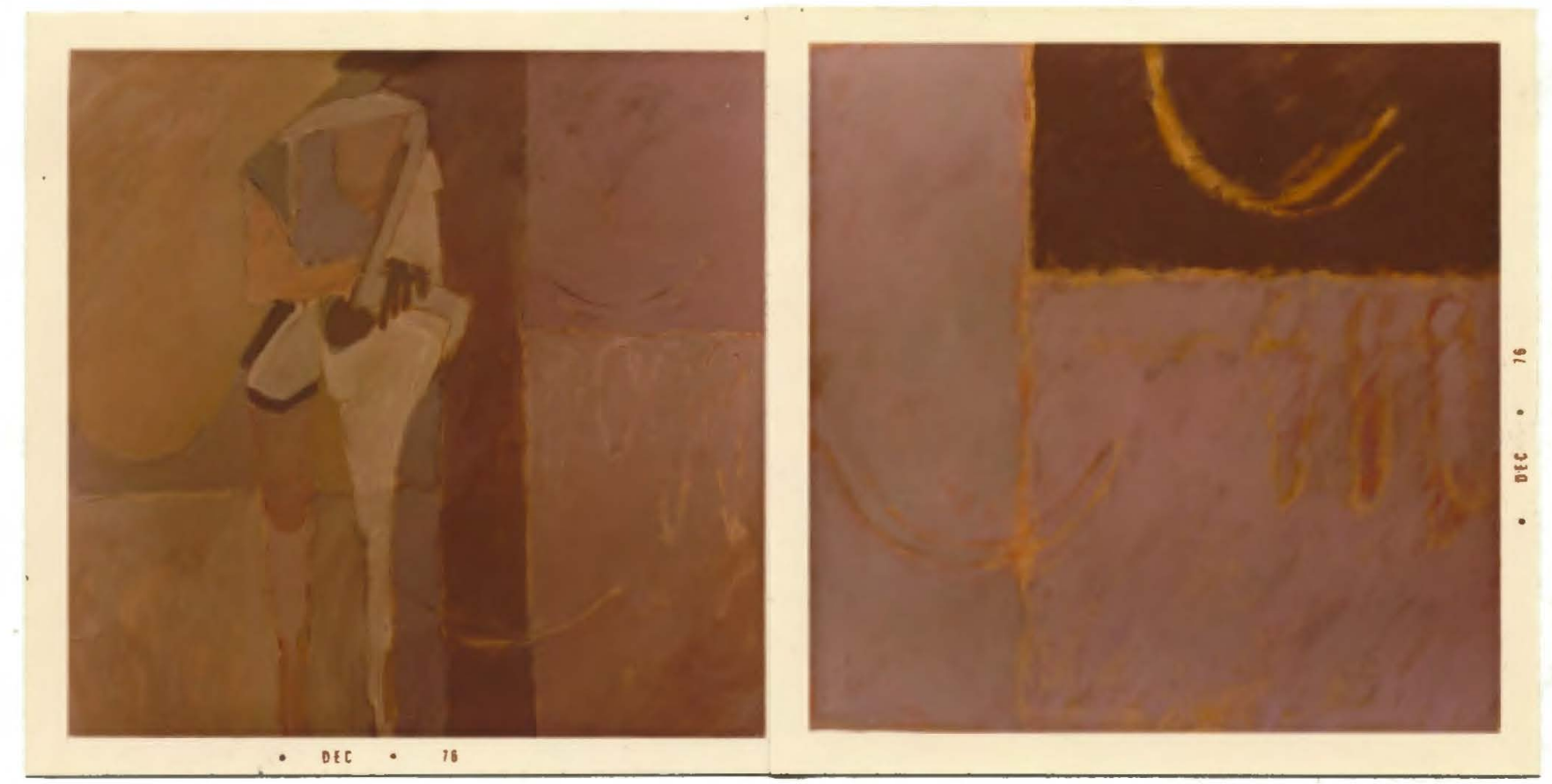

Figure 1. "Carrott Cake" 
the long narrow form next to it. Line is created by paint meeting the edge of a line of oil pastel, or meeting the edge of another area of color. The line and the tension it creates when color reacts with another color is exciting to me. The edge of a brush stroke must be controlled so there is a subtle line created, not too much brush evident, just enough line of the oil pastel. A sort of undulating, alive line was what I was after. I have created containing lines with swift strokes of oil pastel, and softer ones by pulling two colors together creating a line of raw canvas or color mixing.

I was very pleased with the color in this paired painting. The muted umbers of the figure are contrasted by the strong brown mauve in itspair. The field of mauve in this painting is broken only by an occasional line that deliniates form and is successful in doing so by the way the line is handled, seemingly to ebb and flow. In my paintings I try to effect strong sensuous colors that evoke a personal response in the viewer.

The shapes that exist outside the figure and reverberate again in its pair, mainly the arcs, generate rhythmn that is reminicent of notes in a jazz score. I wanted little hits of color, that compared to an improvization by a jazz musician playing in a quartet.

I use the figure more as a catalyst to create form, than as a sociological ideal. I am content if the figure is a strong painterly statement rather than a recognizable intelligent human being. I feel the freedom to manipulate 


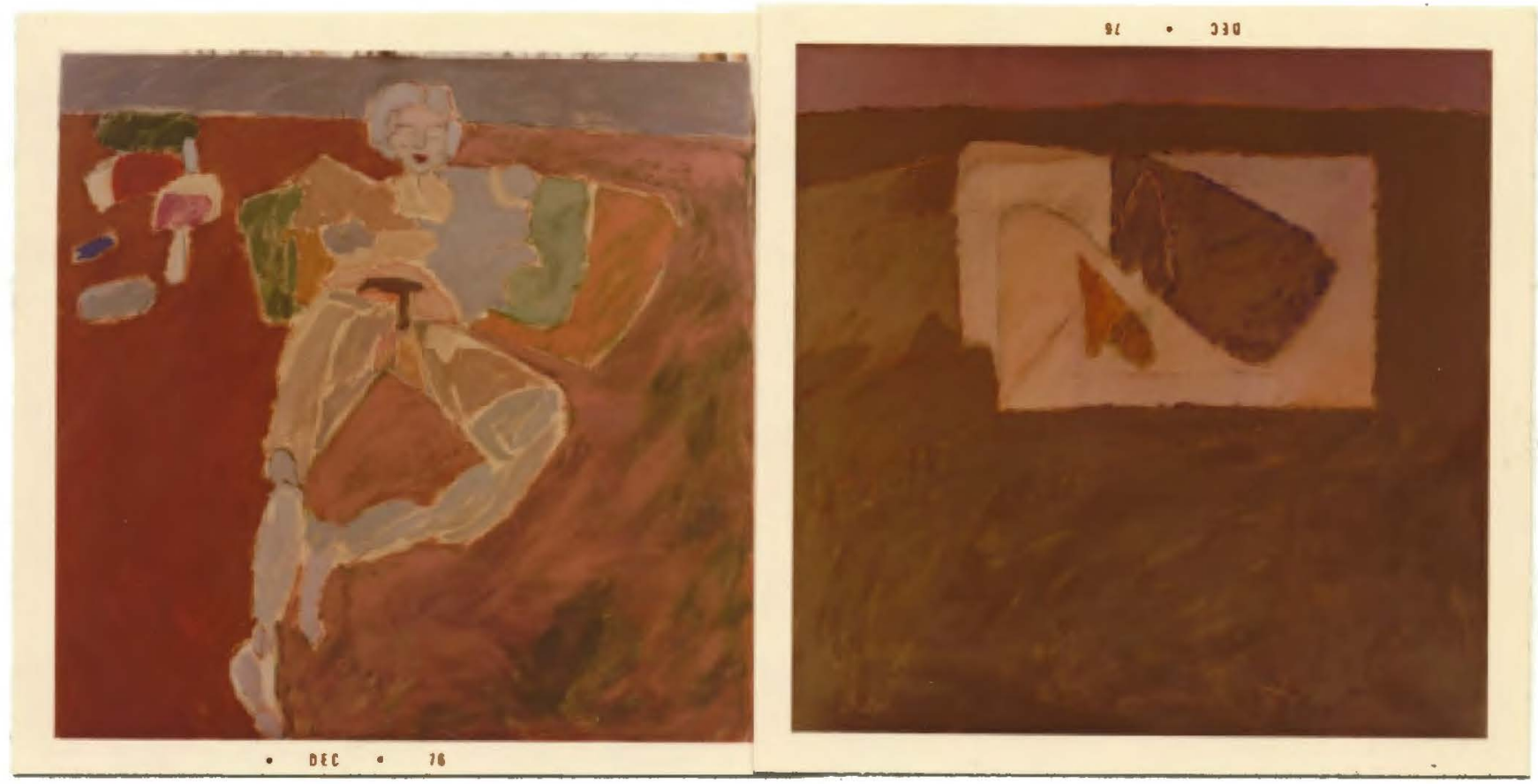

Figure 2. "Cipressa" 
the drawing of the figure to suit my needs and create visual excitement is paramount to any precise rendering. In "Cipressa" the drawing of the figure changes from anotomical correctness to a vague recognition to outright distortion. This perception of the figure has more to do with reality than with verisimilitude.

The handling of the paint in "Cipressa" is done in an energetic manner, with the identity of the brush visible. Underpainting in some areas gives way to the enthusiasm of the brush, as though the brush has a life of its own. The physical action of painting, brushing and scrubbing comes through in this set.

Color mass, like a horizon line, runs behind the figure to connect the two paintings together. The form in the non-figurative painting is one taken from the figure, but exaggerated into an abstract idea. I am especially pleased with the line in the non-figurative piece, the way in contains certain form and energizes them and then recedes and lets color take over as the power source. The line must be fresh and energetic and have an identity of its own. Both paintings have their nuances of color, their peaks, or hits of excitement, then settle down into calm again. Again color is of the utmost importance in the pair. The juxtaposition of greens in the two canvases create tension and balance. I tried to create a sophisticated combination of hues that work together in an unexpected manner, creating a sensuous experience.

Shapes help create the balance and control I am in 


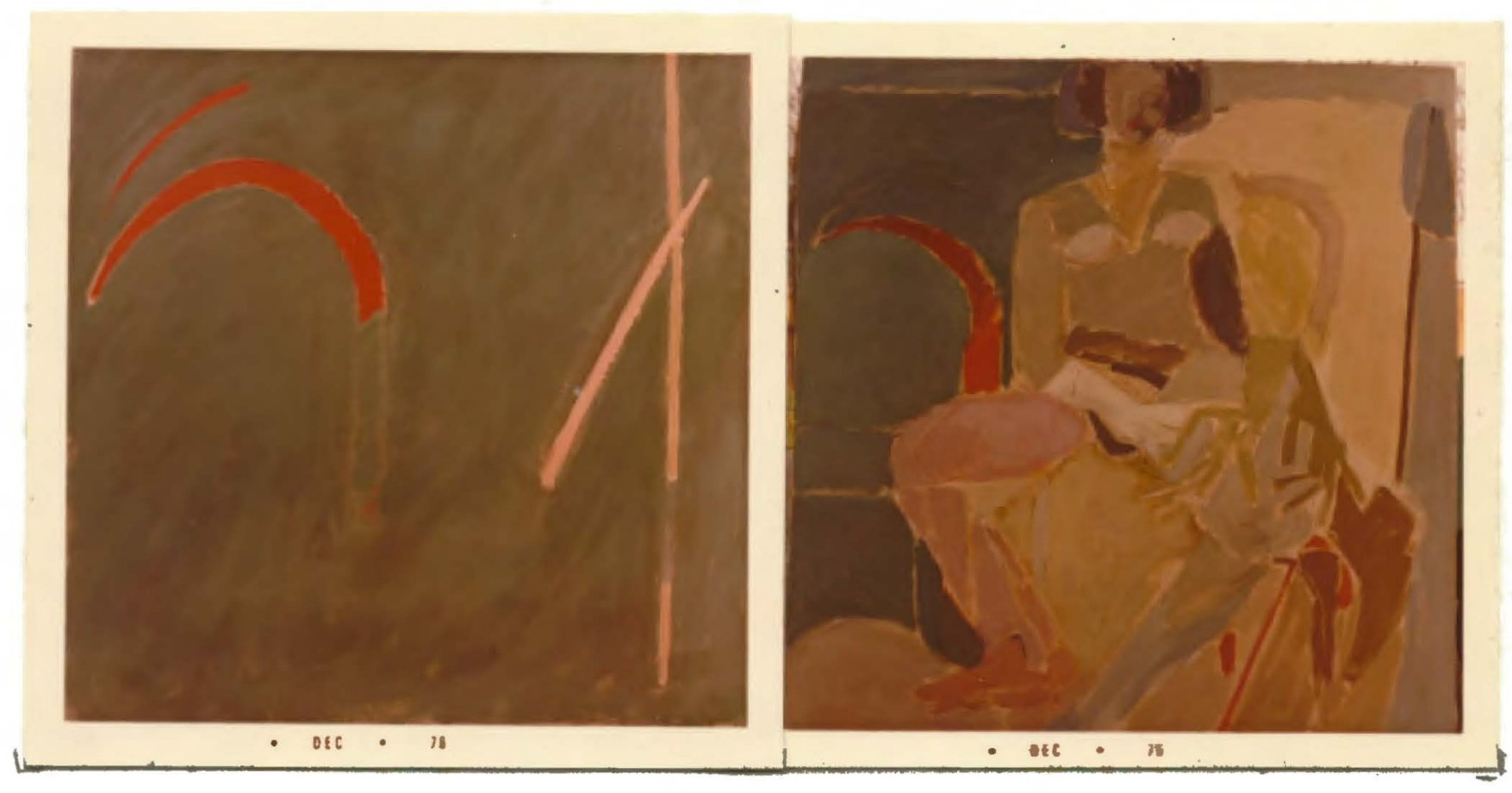

Figure 3. "The Mark on the Wall" 
pursuit of in my paintings, abstract blocks of color, organic forms derived from reality or a line independent of the figure. The figure helps generate this form, but it does not master the painting. In "The Mark on the Wall" the seated figure seems to dominate the canvas, yet the abstract shape in and surrounding the figure act together. Two shapes are taken from the figurative piece and are developed in the non-figurative canvas. They work as stabs of color, notes in a musical score, a sort of color calligraphy. The edges of the two paintings have become important, because of the linking up of the two pieces. The viewer reads parts of the pair as one. The thin vertical stroke of pale peach down the canvas deliniates the beginning of another painting which moves from left to right and ends at the figure, a kind of painting within a painting.

In the two previous pairs, the paintings read in the conventional manner, left to right, as though the figurative work gave birth to the more abstract and non-figurative work. In "The Mark on the Wall", the situation is reversed. This is not to say that one piece is more important because of positioning. It is simply part of the search towards balance, to present the pairs in both directions.

In "The Mark on the Wall", named after a short story by Virginia Woolf, the colors are especially keen to the senses. They seem to evoke reminiscences of the exotic. I think of an oriental silk robe, the dyes of which are still clear after centuries of use. 
My work is a thoroughly personal statement. In putting together the series of paintings, I've tried to reconcile myself to the fact that the end result is a public act, that is, how and where the paintings would hang, who would view them, etcetera, and for me an obvious contradiction. I feel that my paintings demand involvement, more so because of the additional piece, vis à vis Marshal Mcluhan. Accordingly, certain visual art forms require a personal commitment in order to fully understand the work. The viewer must participate in an interaction and give of himself/herself to complete the exchange.

I look at the paintings to know who I am, as in Alice in Wonderland; "... I hardly know sir, just at present -- at least I know who I was when I got up this morning, but I think I must have been changed several times since then." I $100 \mathrm{k}$ at my paintings, I look at what I value. It appears to be a kind of conservatism, that is a search for balance and control and ultimately finding comfort in beauty and simplicity. And putting simplicity together with simplicity results in subtleties that become open ended symbols. Virginia Woolf understood this kind of symbolism that allowed freedom and imagination to play their part in an interpret- 
ation of her work. I hope my pieces convey a part of that spirit. 


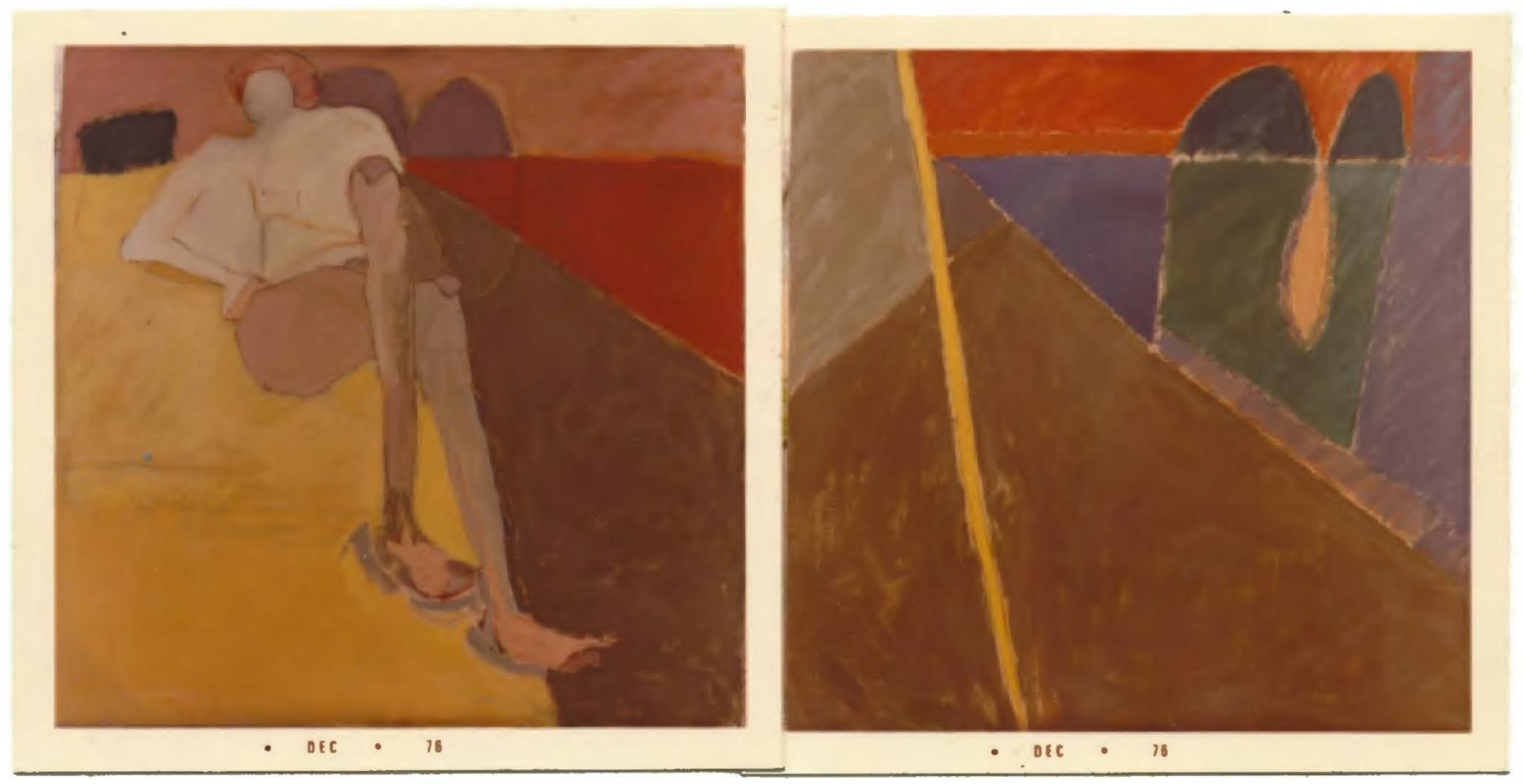

Figure 4. "Orlando" 

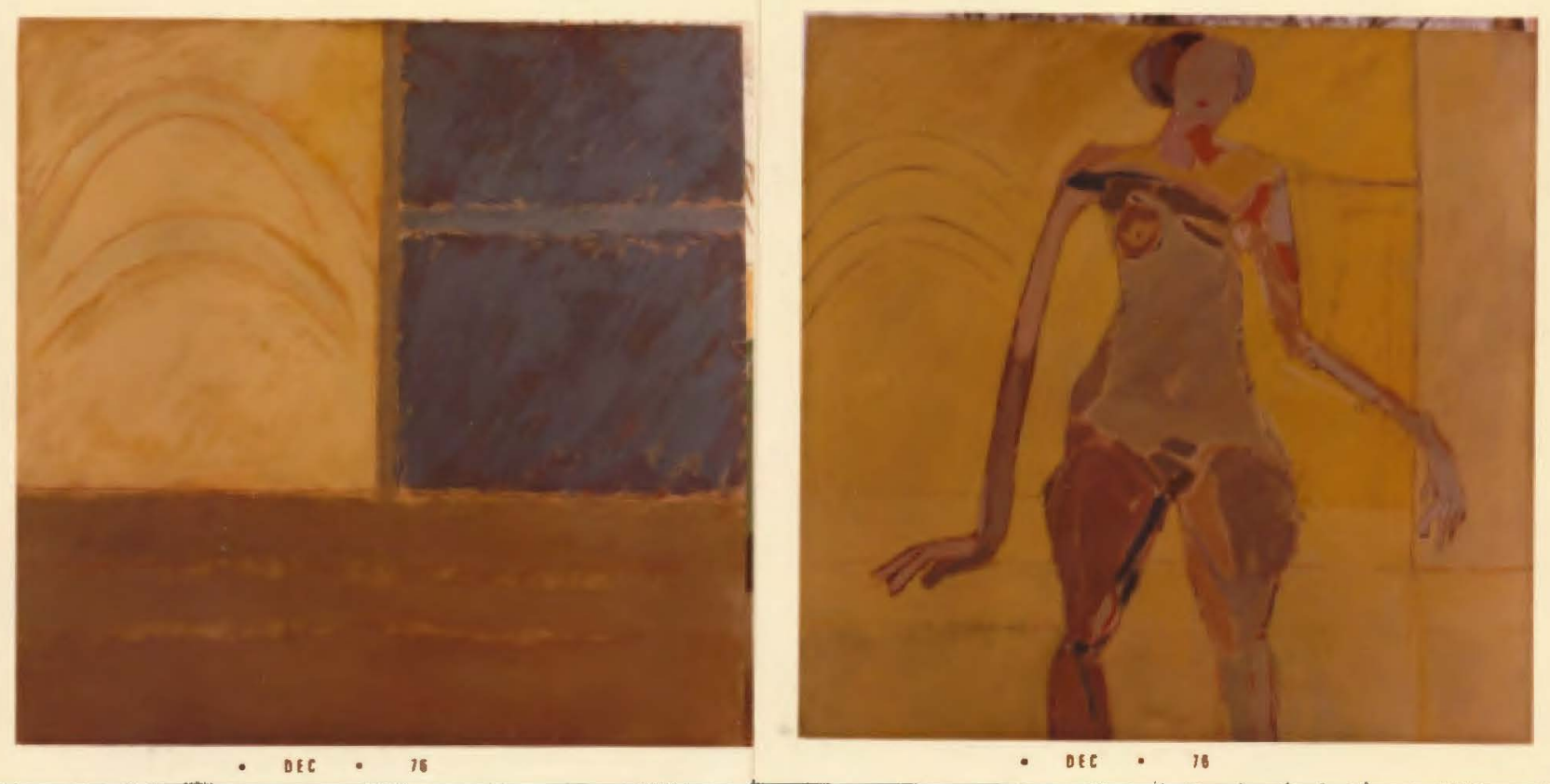

Figure 5. "Lily Briscoe" 


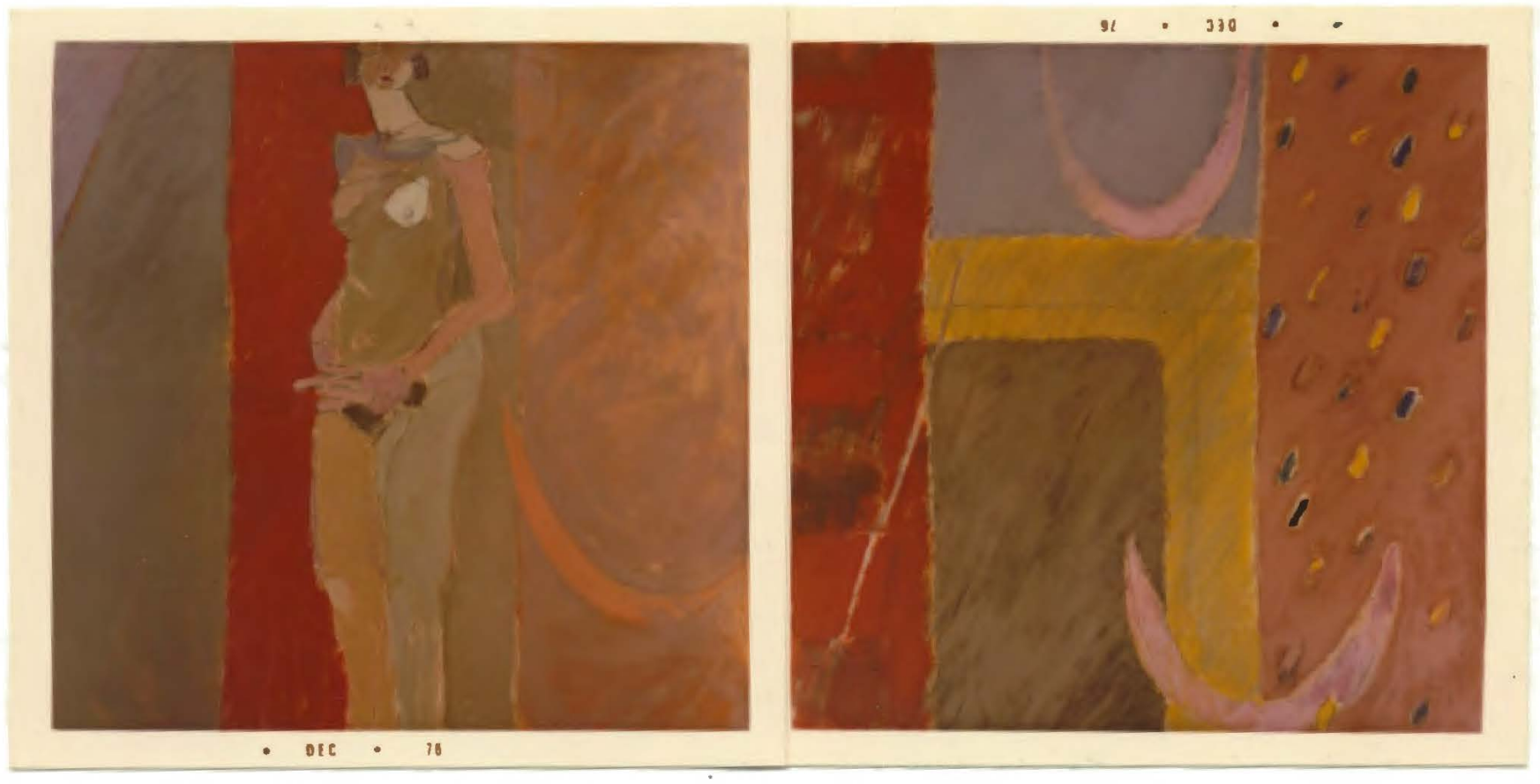

Figure 6. "Nancy" 